\title{
Abra alba populations in and off Arcachon bay (France): mean seasonal evolution of benthic temperatures and salinities from 1971 to 1984
}

\author{
Jean-Marie Bouchet \\ Institut Universitaire de Biologie Marine d'Arcachon (Université de Bordeaux I), 2, rue du Pr. Jolyet, \\ 33120 Arcachon (France)
}

Abra alba populations occur on fine sands outside the Arcachon bay and in several biotopes of the bay, according to the distance from the ocean and the variability of temperatures and salinities. Numerous sectional elevations at the time of high spring tides, show the temperature stratification and the thermal differentiation between the open sea and the inner part of the bay. Only superficial waters penetrate into the lagoon. For example, during summer (July 1983) on the offshore Abra alba community, at depths greater than $30 \mathrm{~m}$, temperatures are $13^{\circ} \mathrm{C}$. A thermal amplitude of 8 degrees separates the two extreme biotopes (distance 27 kilometers), the inner attaining $22^{\circ} \mathrm{C}$. There exists from March to May, and from October to November, a relative thermal homogenization between the bay and the ocean. Salinities are always stratified, and may be very heterogeneous, especially during spring (April and May), when precipitation is particularly frequent. The Eire river, and its numerous tributaries located on the south east of the bay, are the principal sources responsible for lowering salinities.
Five diagrams corresponding to the main biotopes, show the mean seasonal evolution of bottom temperatures and salinities. Months are characterized by fan-shaped curves showing strong tendencies to overlap from year to year. Curves also represent a relative prediction of $\mathrm{T}$ and $\mathrm{S}$ evolution. $\mathrm{A}$ serious cut exists between the ocean and the bay. In the bay itself, another cut marks the Eire estuary. The corresponding diagram may overlap considerably for low salinities during spring and early summer.

Abra alba populations never extend beyond the geographic boundary shown on this last diagram. Their disappearance from the inner part of the Bay occurs during October. Stocks may persist or disappear (Arguin bank, at the mouth of the bay), during winter. Recruitment takes place during spring (March) from the ocean (not yet proven), or from a surviving stock in the bay. 